\title{
Causes of necrotic features in fine-needle aspirates from cervical lymph nodes
}

\author{
Young Jin Seo ${ }^{1}$, Hyeongchan Shin ${ }^{1,2}$, Hye Won Lee ${ }^{1,2}$, Hye Ra Jung ${ }^{1,2}$ \\ 'Department of Pathology, Keimyung University Dongsan Hospital, Daegu; \\ ${ }^{2}$ Department of Pathology, Keimyung University School of Medicine, Daegu, Korea
}

\begin{abstract}
Background: Lymph node fine-needle aspiration (LN FNA) cytology indicates necrosis in various diseases. Dominant necrotic features make the diagnosis of underlying conditions very difficult. Methods: We retrospectively reviewed 460 patients who underwent cervical LN aspiration cytology that revealed necrotic findings at Keimyung University Dongsan Hospital in Daegu, Korea, from 2003-2017. Each specimen was evaluated and analyzed in association with the clinical findings, biopsy findings, and/or other ancillary tests, including acid-fast bacilli staining and molecular testing for Mycobacterium tuberculosis. Results: When necrotic features were noted upon cervical LN FNA cytology, the most common pathologic LN FNA category was necrosis alone (31.5\%). The second most common category was granulomatous inflammation (31.3\%), followed by Kikuchi disease (20.0\%) and malignant neoplasm (8.7\%). In cases where the cervical LN FNA revealed necrosis alone, the most common final diagnosis was tuberculosis. In young patients, Kikuchi disease should be considered as one cervical LN FNA category, while metastatic carcinoma should be suspected in older patients. Conclusions: Even when necrosis alone is observed in LN FNA cytology, it is important to determine the cause through further evaluation.
\end{abstract}

Key Words: Fine-needle aspiration; Lymph node; Necrosis; Tuberculosis; Kikuchi disease

Received: July 20, 2020 Revised: September 16, 2020 Accepted: September 28, 2020

Corresponding Author: Hye Ra Jung, MD, PhD, Department of Pathology, Keimyung University Dongsan Hospital, Department of Pathology, Keimyung University School of Medicine, 1095 Dalgubeol-daero, Dalseo-gu, Daegu 42601, Korea

Tel: +82-53-258-7395, Fax: +82-53-258-7382, E-mail: junghr0519@dsmc.or.kr

Fine-needle aspiration (FNA) is an excellent, minimally invasive diagnostic technique for evaluating a mass or lesion. In particular, FNA is commonly used for evaluating enlarged lymph nodes (LNs). In many cases, the aspirate can provide conclusive evidence for a diagnosis; sometimes, the cytology reveals only necrosis.

Necrosis of LNs is found in various diseases. Malignant neoplasms (including lymphomas and metastatic carcinomas) must first be excluded. In addition, numerous benign conditions, such as tuberculosis (TB) and Kikuchi disease, also cause LN necrosis. When necrosis is identified in an LN FNA cytology sample, pathologists should consider various entities and attempt to find clues that lead to a final diagnosis. However, LN FNA cytology sometimes reveals necrosis alone, and few studies have investigated this situation.

The aim of this study was to evaluate the causes of necrosis in FNA of enlarged LNs.

\section{MATERIALS AND METHODS}

We searched the electronic medical record system of the Keimyung University Dongsan Hospital from 2003-2017 to find patients who underwent FNA on cervical LNs. We selected cases with a description of necrotic features on the pathology report. In addition, we also collected the clinical parameters of these cases, including patient age, sex, biopsy findings, other ancillary tests for Mycobacterium tuberculosis (MTB; including acid-fast bacilli staining), and molecular studies carried out using conventional polymerase chain reaction (PCR) or real-time PCR. We classified these cases into five categories: granulomatous inflammation, Kikuchi disease, suppurative inflammation, malignant neoplasm, and necrosis only. When granuloma was included in the microscopic description (e.g., granulomatous inflammation with caseous necrosis, granulomatous inflammation with a necrotic background, or necrosis with a vague granuloma), it was classi- 
fied as granulomatous inflammation. When the LN FNA result contained content that indicated histiocytic necrotizing inflammation, we placed the patient into the Kikuchi disease category. Cases reported as suspicious for Kikuchi disease with various microscopic descriptions (e.g., necrotizing lymphadenitis, polymorphous lymphoid cells, and macrophages on a necrotic background) were classified as Kikuchi disease. Malignant neoplasms (e.g., metastatic carcinoma, metastatic sarcoma, metastatic melanoma, and malignant lymphoma) with a necrotic background were determined to be malignancies. Cases with suppurative inflammation on a necrotic background, acute inflammatory cells on a necrotic background, aspirated pus, or neutrophilic infiltration with necrotic material were classified as suppurative inflammation.

\section{RESULTS}

\section{Clinical characteristics of the patients}

We retrieved the electronic medical reports of 460 patients who underwent LN aspiration cytology at our hospital that revealed necrotic features. The mean age of the patients was 42.5 years (range, 2 to 86 years; median, 40 years). The male-to-female ratio (M:F ratio) was 0.62. Except for cases of pure necrosis, the most common FNA category was granulomatous inflammation (31.3\%), followed by Kikuchi lymphadenitis (20.0\%), malignancy $(8.7 \%)$, and suppurative lymphadenitis (6.5\%) (Table 1 ).

\section{Granulomatous inflammation}

Of the 460 patients, 144 were classified with granulomatous inflammation from among the LN FNA categories. The M:F ratio was 0.38 . This type of inflammation was mainly distributed in people from 20-39 years of age (36.8\%). Of the 144 patients with granulomatous inflammation, 117 underwent ancillary tests for MTB; 82 (70.0\%) of these were diagnosed with TB. In addition, MTB testing was performed in 364 of the 460 total cases who underwent cervical LN FNA. Among these patients, 148 cases were MTB-positive, which represented 32\% of all cervical LN FNA cases (Table 2).

Table 1. The age and sex distribution of cervical LN FNA categories according to the FNA diagnosis

\begin{tabular}{|c|c|c|c|c|c|}
\hline FNA category & Mean age (yr) & Age range (yr) & Men (person) & Women (person) & Total (\%) \\
\hline \multirow[t]{5}{*}{ Granulomatous inflammation (31.3\%) } & 46.0 & $0-19$ & 4 & 4 & 8 \\
\hline & & $20-39$ & 14 & 39 & 53 \\
\hline & & $40-59$ & 13 & 32 & 45 \\
\hline & & $<60$ & 9 & 29 & 38 \\
\hline & & Total & 40 & 104 & 144 \\
\hline \multirow[t]{5}{*}{ Kikuchi disease (20.0\%) } & 26.4 & $0-19$ & 15 & 16 & 31 \\
\hline & & 20-39 & 14 & 37 & 51 \\
\hline & & $40-59$ & 1 & 8 & 9 \\
\hline & & $<60$ & 0 & 1 & 1 \\
\hline & & Total & 30 & 62 & 92 \\
\hline \multirow[t]{5}{*}{ Suppurative inflammation (6.5\%) } & 40.8 & $0-19$ & 0 & 5 & 5 \\
\hline & & $20-39$ & 5 & 4 & 9 \\
\hline & & $40-59$ & 4 & 7 & 11 \\
\hline & & $<60$ & 3 & 2 & 5 \\
\hline & & Total & 12 & 18 & 30 \\
\hline \multirow[t]{5}{*}{ Malignant neoplasm (8.7\%) } & 61.9 & 0-19 & 0 & 0 & 0 \\
\hline & & $20-39$ & 1 & 0 & 1 \\
\hline & & $40-59$ & 8 & 6 & 14 \\
\hline & & $<60$ & 24 & 1 & 25 \\
\hline & & Total & 33 & 7 & 40 \\
\hline \multirow[t]{5}{*}{ Necrosis (31.5\%) } & 44.0 & $0-19$ & 5 & 6 & 11 \\
\hline & & $20-39$ & 22 & 33 & 55 \\
\hline & & $40-59$ & 13 & 36 & 49 \\
\hline & & $<60$ & 15 & 15 & 30 \\
\hline & & Total & 55 & 90 & 145 \\
\hline Other (2.0\%) & 46.0 & Total & 5 & 4 & 9 \\
\hline Total & 42.5 & & 175 & 285 & 460 \\
\hline
\end{tabular}

LN, lymph node; FNA, fine-needle aspiration. 


\section{Kikuchi disease}

Ninety-two patients who underwent LN FNA were determined to have Kikuchi disease. Of these 92 people, $89.1 \%$ were young ( $<40$ years). The M:F ratio was approximately 1:2. Thirteen of these patients classified as having Kikuchi disease by LN FNA underwent ancillary tests for MTB. Among them, 11

Table 2. The results of ancillary tests for Mycobacterium tuberculosis in the granulomatous inflammation, Kikuchi disease, suppurative lymphadenitis, malignant neoplasm, and necrosis categories of cervical LN FNA findings

\begin{tabular}{|c|c|c|c|c|}
\hline FNA category & Related Bx & MTB & Biopsy Dx & No. of cases \\
\hline \multirow[t]{8}{*}{ Granulomatous inflammation } & Present & Positive & $\mathrm{ND}$ & 3 \\
\hline & & Negative & Granulomatous inflammation & 7 \\
\hline & & & Kikuchi disease & 2 \\
\hline & & & Lymphoma & 2 \\
\hline & & ND & Metastatic squamous cell carcinoma & 1 \\
\hline & Absent & Positive & ND & 79 \\
\hline & & Negative & ND & 24 \\
\hline & & ND & ND & 26 \\
\hline \multirow[t]{6}{*}{ Kikuchi disease } & Present & Positive & ND & 0 \\
\hline & & Negative & Preauricular pit & 1 \\
\hline & & ND & Kikuchi disease & 1 \\
\hline & Absent & Positive & ND & 2 \\
\hline & & Negative & ND & 10 \\
\hline & & ND & $\mathrm{ND}$ & 78 \\
\hline \multirow[t]{7}{*}{ Supprative lymphadenitis } & Present & Negative & Granulomatous inflammation & 1 \\
\hline & & & Metastatic carcinoma & 1 \\
\hline & & & Warthin's tumor & 1 \\
\hline & & ND & Metastatic carcinoma & 1 \\
\hline & Absent & Positive & ND & 11 \\
\hline & & Negative & ND & 7 \\
\hline & & $\mathrm{ND}$ & ND & 8 \\
\hline \multirow[t]{7}{*}{ Malignant neoplasm } & Present & Negative & Adenocarcinoma & 1 \\
\hline & & ND & Adenocarcinoma & 4 \\
\hline & & & Diffuse large B-cell lymphoma & 2 \\
\hline & & & Malignant tumor, unclassified & 1 \\
\hline & & & Other metastatic carcinoma & 2 \\
\hline & & & Small cell carcinoma & 7 \\
\hline & & & Squamous cell carcinoma & 23 \\
\hline \multirow[t]{14}{*}{ Necrosis } & Present & Positive & $\mathrm{ND}$ & 4 \\
\hline & & Negative & Granulomatous inflammation & 4 \\
\hline & & & Infarct & 1 \\
\hline & & & Kikuchi disease & 3 \\
\hline & & & Lymphoma & 2 \\
\hline & & & Other mimickers & 5 \\
\hline & & ND & Granulomatous inflammation & 1 \\
\hline & & & infarct & 1 \\
\hline & & & Kikuchi & 1 \\
\hline & & & Lymphoma & 2 \\
\hline & & & Other mimickers & 3 \\
\hline & Absent & Positive & ND & 49 \\
\hline & & Negative & ND & 28 \\
\hline & & ND & ND & 41 \\
\hline \multirow[t]{4}{*}{ Others } & Present & ND & Reactive hyperplasia & 1 \\
\hline & & & Granulomatous inflammation & 1 \\
\hline & Absent & Negative & $\mathrm{ND}$ & 1 \\
\hline & & $\mathrm{ND}$ & ND & 6 \\
\hline
\end{tabular}

LN, lymph node; FNA, fine-needle aspiration; Related Bx, presence or absence of biopsy on related site of fine needle biopsy; MTB, result of ancillary tests including acid-fast bacillus stain, polymerase chain reaction or reverse transcription polymerase chain reaction for Mycobacterium tuberculosis; Biopsy Dx, diagnosis by related site biopsy; ND, not done. 

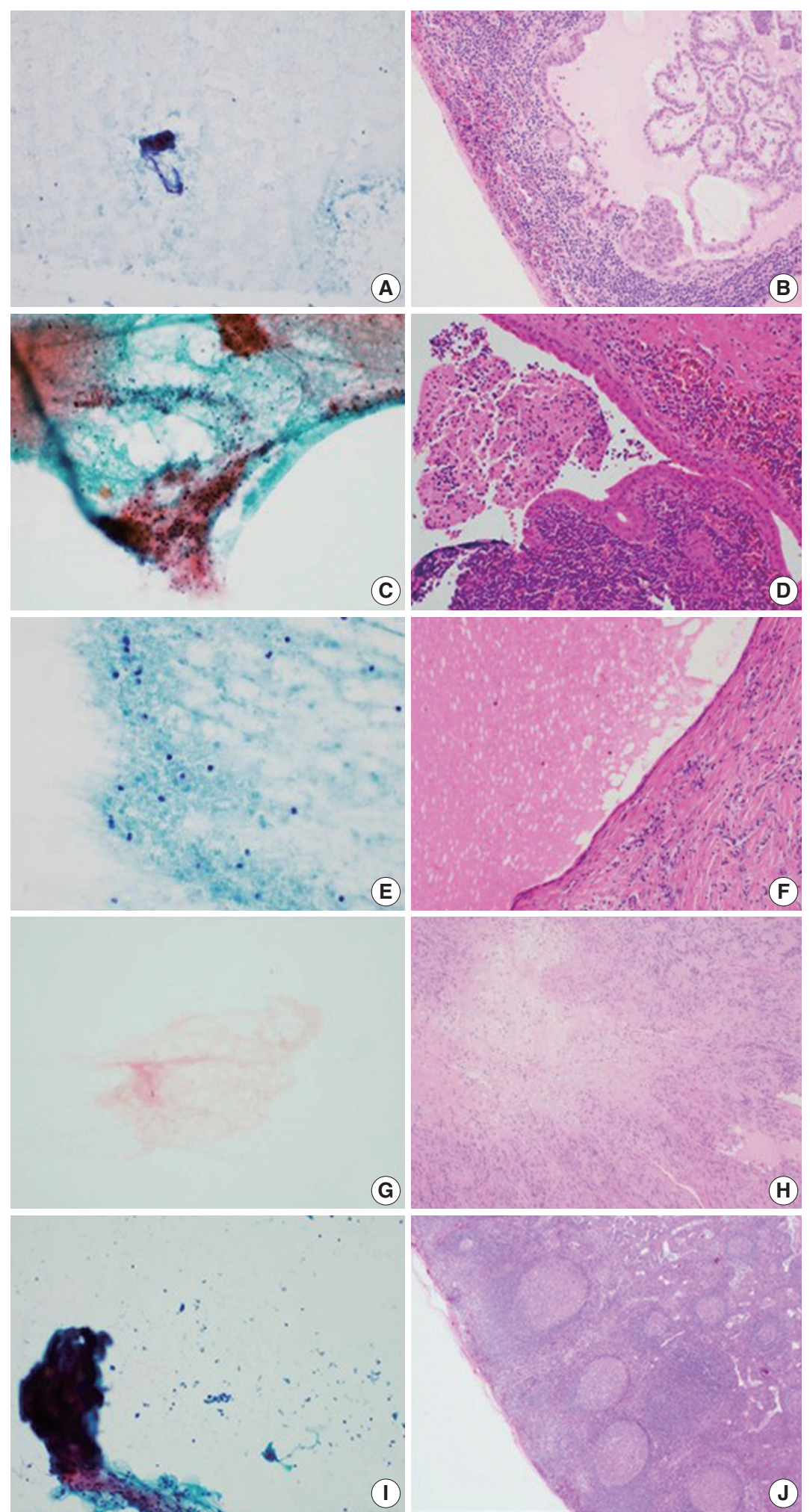

Fig. 1. Smear and biopsy findings of the neck lesion diagnosed as necrosis on aspiration but changed diagnosis by biopsy (A, B). (A) Fine needle aspiration (FNA) shows colloid material. (B) Lymph node (LN) excision specimen was diagnosed as metastatic papillary carcinoma. (C, D) Case 2. (C) FNA shows pinkish amorphous material. (D) LN excision specimen was diagnosed as Warthin tumor. (E, F) Case 3. (E) FNA shows cystic fluid material. (F) LN excision specimen was diagnosed as salivary duct cyst. (G, H) Case 4. (G) FNA shows myxoid stroma. (H) LN excision specimen was diagnosed as schwannoma. (I, J) Case 5. (I) FNA shows red blood cells and fibrin material. (J) LN excision specimen was diagnosed as reactive hyperplasia. 
patients were negative, but the remaining two patients had positive results. Therefore, the final diagnosis of 11 patients was TB.

\section{Suppurative lymphadenitis}

Of the 460 total patients, 30 (6.7\%) were classified with suppurative lymphadenitis. Twenty-five patients $(83.3 \%)$ were $<60$ years of age. The $\mathrm{M}: \mathrm{F}$ ratio was 0.67 . Among these 30 patients, 21 underwent ancillary tests for MTB. Eleven patients received a final diagnosis of TB. Four of the 10 patients who were negative for MTB underwent LN biopsy and were finally diagnosed with granulomatous inflammation, Warthin tumor, and metastatic carcinoma (Table 2).

\section{Malignant neoplasm}

In 40 patients, malignant neoplasms were classified into distinct LN FNA categories. The average patient age was 61.9 years. The M:F ratio was 4:7. All 40 patients underwent LN biopsies in the same region. Metastatic carcinoma accounted for $92.5 \%$ of cases. Among these cases, the incidence of squamous cell carcinoma was $62.2 \%$. Two cases of malignant lymphoma were diffuse large B-cell lymphomas. In young patients, many cases were diagnosed as TB, while some older patients had metastatic carcinoma.

\section{Necrosis alone}

Of the 460 cases, 145 were classified as having necrosis alone; 94 cases underwent ancillary testing for MTB, and 53 patients (56.4\%) were diagnosed with TB. In addition, 27 patients received an LN biopsy. These remaining cases were finally diagnosed with granuloma, Kikuchi disease, necrosis, lymphomas, and other disorders (Table 2). Seven other mimickers included reactive hyperplasia $(\mathrm{n}=2)$, metastatic papillary carcinoma $(\mathrm{n}=$ $1)$, Warthin tumor $(\mathrm{n}=1)$, salivary duct cyst $(\mathrm{n}=1)$, schwanno$\mathrm{ma}(\mathrm{n}=1)$, and spindle cell tumor $(\mathrm{n}=1)$ (Fig. 1$)$.

\section{DISCUSSION}

FNA is frequently performed as a minimally invasive procedure in patients with mass lesions of superficial organs. It is also a very useful test for clinicians to use when deciding on a treatment. However, the FNA cytology slides may offer no diagnostic clues. In some cases, the cellularity is too low and reveals only necrotic material. In these situations, the pathologist faces diffculties in arriving at a diagnosis. Necrosis is common in benign inflammatory lesions as well as in metastatic malignancies. Extensive necrosis is known to accompany not only metastatic ma- lignancy, but also acute inflammation or granulomatous inflammation. In addition, focal necrosis is seen in LNs associated with systemic lupus erythematosus, infectious mononucleosis, and brucellosis [1].

We reviewed the literature on LN FNAs that reveal necrotic features. The most common reports were on TB [2-11], followed by studies on lymphoma [12-19] and metastatic lesions [20-23] (Table 3). However, most of these studies were case reports. There have been very few systematic reports of cases where necrosis is observed or certain diseases must be considered to be more important based on the patient age.

In this study, we analyzed 460 patients who underwent cervical LN FNA cytology that revealed necrotic features. The most common causative disease was TB. Of the 460 patients, 247 underwent ancillary testing for MTB, and 148 (59.9\%) were finally diagnosed with TB. Typically, the most characteristic cytologic findings of TB are nodular collections of epithelioid histiocytes with Langhans giant cells and caseous necrosis. However, either end of the cytologic spectrum may be seen, especially necrosis without granulomas [24]. Kumar et al. [5] reported that the presence of acute lymphadenitis does not completely exclude TB. They clinically suspected TB in 263 cases with a cytologic picture that demonstrated acute suppurative inflammation. LN FNA should be repeated in all FNA cases that show acute suppurative inflammation without granulomas. It has been reported that a repeat LN FNA helps to detect more than $55 \%$ of additional TB cases [25]. In this study, among the patients classified with suppurative lymphadenitis according to FNA cytology, $36.7 \%$ were finally diagnosed with TB following ancillary tests. Therefore, it is important to rule out TB when necrotic features are noted on LN FNA cytology.

Necrotic features may also be characteristic of the Kikuchi disease category in cervical LN FNA. The FNA findings in Kikuchi disease typically reveal a polymorphous lymphoid population, crescentic histiocytes, extensive apoptotic bodies, and necrosis. The combination of crescentic histiocytes and karyorrhectic debris suggests the diagnosis of Kikuchi disease. However, some cases show only karyorrhexis and necrosis, which is not specific for Kikuchi disease. For example, infectious mononucleosis may rarely demonstrate extensive necrosis. Infectious mononucleosis is a self-limited viral disease that frequently involves the cervical LNs of young patients who present with fever and pharyngitis. In infectious mononucleosis, a polymorphous infiltrate with atypical large lymphoid cells is usually noted. The patient's clinical history is helpful in arriving at a differential diagnosis in these cases [26]. 
Another important cause of necrotic features in cervical LN FNA cytology is malignant neoplasm. Among our 460 cases, 49 were finally confirmed as malignancies (including metastatic carcinoma) by tissue biopsy. The mean age of these patients was 62 years. Forty cases were metastatic carcinoma. Among these cases, the most common malignancy was squamous cell carcinoma $(62.5 \%)$. This trend was consistent with the findings of previous reports. In squamous cell carcinoma, metastatic LNs of the head and neck are often the first signs of malignancy in the inconspicuous organs of this region [1]. Additionally, cystic changes are often observed in metastatic LNs in squamous cell carcinoma [27]. Necrotic material may also be identified in the cyst spaces; therefore, pathologists should be mindful during their microscopic examinations. In our study, most cases were diagnosed as malignant neoplasms by FNA alone; the remaining nine cases were diagnosed as suppurative lymphadenitis $(n=1)$, granuloma $(n=3)$, and necrosis $(n=5)$ of the LNs. Therefore, when necrotic features are seen in the cervical LN FNA cytology in older patients, pathologists should consider the possibility of malignancy and carefully correlate their findings with the clinical history of the patient to ensure the proper evaluation is recommended to clinicians, even though there may be a paucity of cells on the smeared slides.

In this study, we identified misdiagnosed cases of cervical LN necrosis on FNA. Following an excision biopsy, these cases were diagnosed as reactive hyperplasia, salivary duct cysts, Warthin tumors, schwannomas, and spindle cell tumors. As demonstrated by these cases, fibrinoid material that is present due to excessive

Table 3. Previously published reports with the keywords "FNA," "necrosis," and "lymph node"

\begin{tabular}{|c|c|c|c|c|}
\hline Category & Diagnosis & Journal & First author & $\begin{array}{c}\text { Publication } \\
\text { Year }\end{array}$ \\
\hline \multirow[t]{15}{*}{ Infection $(n=17)$} & Cat scratch disease $(n=1)$ & Am J Clin Pathol & Choi AH [28] & 2015 \\
\hline & Histoplasmosis $(n=1)$ & Cancer Cytopathol & Gailey MP [29] & 2013 \\
\hline & Infection $(n=1)$ & J Thorac Oncol & Aerts JG [30] & 2008 \\
\hline & \multirow[t]{9}{*}{ Tuberculosis $(n=11)$} & Diagn Cytopathol & Das DK [3] & 1992 \\
\hline & & Am J Clin Pathol & Lapuerta P [31] & 1997 \\
\hline & & Cytopathology & Kumar N [5] & 1998 \\
\hline & & World J Gastroenterol & Xia F [7] & 2003 \\
\hline & & Cytopathology & Aljafari AS [2] & 2004 \\
\hline & & Southeast Asian J Trop Med Public Health & Chantranuwat C [6] & 2006 \\
\hline & & J Gastroenterol & Itaba S [9] & 2007 \\
\hline & & Int J Tuberc Lung Dis & Berzosa M [8] & 2010 \\
\hline & & Ann Thorac Surg & Sun J [11] & 2013 \\
\hline & \multirow[t]{3}{*}{ Tularemia $(n=3)$} & Infection & Ulu-Kilic A [32] & 2013 \\
\hline & & APMIS & Tuncer E [33] & 2014 \\
\hline & & Acta Cytol & Markoc F [34] & 2014 \\
\hline \multirow[t]{2}{*}{ Kikuchi disease $(n=2)$} & \multirow[t]{2}{*}{ Kikuchi disease $(n=2)$} & Diagn Cytopathol & Hsueh EJ [35] & 1993 \\
\hline & & Diagn Cytopathol & Viguer JM [36] & 2001 \\
\hline \multirow[t]{7}{*}{ Lymphoma $(\mathrm{n}=8)$} & \multirow[t]{2}{*}{ Hodgkin lymphoma ( $n=2)$} & Diagn Cytopathol & Florentine BD [12] & 2014 \\
\hline & & J Clin Exp Hematop & Okuni M [13] & 2018 \\
\hline & Langerhans cell histiocytosis $(n=1)$ & Cytopathology & Phulware RH [14] & 2019 \\
\hline & \multirow[t]{4}{*}{ Non-Hodgkin lymphoma $(n=5)$} & Acta Cytol & Tani E [16] & 1989 \\
\hline & & Acta Cytol & Sneige N [15] & 1990 \\
\hline & & Leuk Lymphoma & Dao TH [17] & 1991 \\
\hline & & Diagn Cytopathol & Dunphy CH [18] & 1997 \\
\hline \multirow[t]{4}{*}{ Metastatic lesion $(n=4)$} & \multirow[t]{4}{*}{ Squamous cell carcinoma $(n=4)$} & Diagn Cytopathol & Allison DB [22] & 2016 \\
\hline & & Cytojournal & Lastra RR [21] & 2013 \\
\hline & & Diagn Cytopathol & Banet N [20] & 2016 \\
\hline & & Cytopathology & Rollo F [23] & 2018 \\
\hline \multirow[t]{3}{*}{ Other $(n=3)$} & Paraganglioma $(n=1)$ & Diagn Cytopathol & Fite JJ [37] & 2018 \\
\hline & \multirow[t]{2}{*}{ Sarcoidosis $(n=2)$} & Eur Respir J & Annema JT [38] & 2005 \\
\hline & & Coll Antropol & Vrbica Z [39] & 2010 \\
\hline
\end{tabular}


hemorrhaging, amorphous material of tumor components, or hypocellular myxoid stroma could be confused with a necrotic background.

An accurate diagnosis on cervical LN FNA cytology is important to determine the most appropriate treatment and to prevent unnecessary surgery. This study was conducted in the Republic of Korea, and we found that the most common cause of necrosis in cervical LN FNA cytology was TB. When there are necrotizing features in the FNA of the cervical lymph nodes in young patients, Kikuchi disease should be considered first. Metastatic carcinoma should always be suspected in older patients, even if they do not have any previous history of malignancy. In addition, when necrotizing features are noted in the FNA of the cervical lymph nodes of patients in any age group, MTB testing should be performed in parallel to exclude TB, which has a high prevalence in the Republic of Korea.

\section{Ethics Statement}

This study was approved by the Institutional Review Board of the Keimyung University Dongsan Hospital with a waiver of informed consent (DSMC 2020-03-069-002) and performed in accordance with the principles of the Declaration of Helsinki.

\section{ORCID}

Young Jin Seo https://orcid.org/0000-0002-9048-0903

Hyeongchan Shin https://orcid.org/0000-0002-3716-7678

Hye Won Lee https://orcid.org/0000-0001-8540-524X

Hye Ra Jung https://orcid.org/0000-0002-1477-6606

\section{Author Contributions}

Conceptualization: HRJ. Data curation: YJS, HS. Formal analysis: YJS, HRJ. Methodology: YJS, HRJ. Supervision: HRJ. Visualization: YJS, HWL. Writing_original draft: YJS, HRJ. Writing—review \& editing: YJS, HS, HWL, HRJ. Approval of final manuscript: all authors.

\section{Conflicts of Interest}

The authors declare that they have no potential conflicts of interest.

\section{Funding Statement}

No funding to declare.

\section{References}

1. van Schaik JE, Muller Kobold AC, van der Laan B, van der Vegt B, van Hemel BM, Plaat BEC. Squamous cell carcinoma antigen concentration in fine needle aspiration samples: a new method to detect cervical lymph node metastases of head and neck squamous cell carcinoma. Head Neck 2019; 41: 2561-5.

2. Aljafari AS, Khalil EA, Elsiddig KE, et al. Diagnosis of tuberculous lymphadenitis by FNAC, microbiological methods and PCR: a comparative study. Cytopathology 2004; 15: 44-8.

3. Das DK, Bhambhani S, Pant JN, et al. Superficial and deep-seated tuberculous lesions: fine-needle aspiration cytology diagnosis of 574 cases. Diagn Cytopathol 1992; 8: 211-5.
4. Ersoz C, Polat A, Serin MS, Soylu L, Demircan O. Fine needle aspiration (FNA) cytology in tuberculous lymphadenitis. Cytopathology 1998; 9: 201-7.

5. Kumar N, Tiwari MC, Verma K. AFB staining in cytodiagnosis of tuberculosis without classical features: a comparison of ZiehlNeelsen and fluorescent methods. Cytopathology 1998; 9: 208-14.

6. Chantranuwat C, Assanasen T, Shuangshoti S, Sampatanukul P. Polymerase chain reaction for detection of Mycobacterium tuberculosis in papanicolaou-stained fine needle aspirated smears for diagnosis of cervical tuberculous lymphadenitis. Southeast Asian J Trop Med Public Health 2006; 37: 940-7.

7. Xia F, Poon RT, Wang SG, Bie P, Huang XQ, Dong JH. Tuberculosis of pancreas and peripancreatic lymph nodes in immunocompetent patients: experience from China. World J Gastroenterol 2003; 9: 1361-4.

8. Berzosa M, Tsukayama DT, Davies SF, et al. Endoscopic ultrasound-guided fine-needle aspiration for the diagnosis of extra-pulmonary tuberculosis. Int J Tuberc Lung Dis 2010; 14: 578-84.

9. Itaba S, Yoshinaga S, Nakamura K, et al. Endoscopic ultrasoundguided fine-needle aspiration for the diagnosis of peripancreatic tuberculous lymphadenitis. J Gastroenterol 2007; 42: 83-6.

10. Mittal P, Handa U, Mohan H, Gupta V. Comparative evaluation of fine needle aspiration cytology, culture, and PCR in diagnosis of tuberculous lymphadenitis. Diagn Cytopathol 2011; 39: 822-6.

11. Sun J, Teng J, Yang H, et al. Endobronchial ultrasound-guided transbronchial needle aspiration in diagnosing intrathoracic tuberculosis. Ann Thorac Surg 2013; 96: 2021-7.

12. Florentine BD, Cohen AN. Nodular sclerosing classical Hodgkin lymphoma masquerading as acute suppurative-necrotizing lymphadenitis. Diagn Cytopathol 2014; 42: 238-41.

13. Okuni M, Yakushijin K, Sakai Y, et al. A case of classical Hodgkin lymphoma with total lymph node infarction. J Clin Exp Hematop 2018; 58: 24-6.

14. Phulware RH, Guleria P, Iyer VK, et al. Cytological diagnosis of Langerhans cell histiocytosis: a series of 47 cases. Cytopathology 2019; 30: 413-8.

15. Sneige N, Dekmezian RH, Katz RL, et al. Morphologic and immunocytochemical evaluation of 220 fine needle aspirates of malignant lymphoma and lymphoid hyperplasia. Acta Cytol 1990; 34: 311-22.

16. Tani E, Liliemark J, Svedmyr E, Mellstedt H, Biberfeld P, Skoog L. Cytomorphology and immunocytochemistry of fine needle aspirates from blastic non-Hodgkin's lymphomas. Acta Cytol 1989; 33: 363-71.

17. Dao TH, Fleury-Feith J, Haioun C, et al. Percutaneous fine needle aspiration cytology and biopsy in the diagnosis and classification of lymphoma: clinical evaluation. Leuk Lymphoma 1991; 5: 237-42.

18. Dunphy CH, Ramos R. Combining fine-needle aspiration and flow cytometric immunophenotyping in evaluation of nodal and extranodal sites for possible lymphoma: a retrospective review. Diagn Cytopathol 1997; 16: 200-6.

19. Handa U, Mohan H, Punia RS, Nada R. FNAC in a case of NHL presenting initially as nodal infarction. Indian J Pathol Microbiol 2005; 48: 510-2.

20. Banet N, Rooper LM, Maleki Z. Metastatic HPV-related head and neck squamous cell carcinoma to the lung and mediastinal lymph nodes in aspirated cytology material: a diagnostic pitfall. Diagn Cytopathol 2016; 44: 206-14.

21. Lastra RR, Pramick MR, Nakashima MO, et al. Adequacy of fine- 
needle aspiration specimens for human papillomavirus infection molecular testing in head and neck squamous cell carcinoma. Cytojournal 2013; 10: 21.

22. Allison DB, Bishop JA, Ali SZ. Cytopathologic characteristics of SMARCB1 (INI-1) deficient sinonasal carcinoma: a potential diagnostic pitfall. Diagn Cytopathol 2016; 44: 700-3.

23. Rollo F, Dona MG, Pellini R, et al. Cytology and direct human papillomavirus testing on fine needle aspirates from cervical lymph node metastases of patients with oropharyngeal squamous cell carcinoma or occult primary. Cytopathology 2018; 29: 449-54.

24. Mac DeMay R. The art and science of cytopathology. Chicago: American Society for Clinical Pathology, 2012.

25. Kumar N, Jain S, Murthy NS. Utility of repeat fine needle aspiration in acute suppurative lesions: follow-up of 263 cases. Acta Cytol 2004; 48: 337-40.

26. Tong TR, Chan OW, Lee KC. Diagnosing Kikuchi disease on fine needle aspiration biopsy: a retrospective study of 44 cases diagnosed by cytology and 8 by histopathology. Acta Cytol 2001; 45: 953-7.

27. Mokhtari S. Mechanisms of cyst formation in metastatic lymph nodes of head and neck squamous cell carcinoma. Diagn Pathol 2012; 7: 6 .

28. Choi AH, Bolaris M, Nguyen DK, Panosyan EH, Lasky JL 3rd, Duane GB. Clinicocytopathologic correlation in an atypical presentation of lymphadenopathy with review of literature. Am J Clin Pathol 2015; 143: 749-54.

29. Gailey MP, Klutts JS, Jensen CS. Fine-needle aspiration of histoplasmosis in the era of endoscopic ultrasound and endobronchial ultrasound: cytomorphologic features and correlation with clinical laboratory testing. Cancer Cytopathol 2013; 121: 508-17.

30. Aerts JG, Kloover J, Los J, van der Heijden O, Janssens A, Tournoy
KG. EUS-FNA of enlarged necrotic lymph nodes may cause infectious mediastinitis. J Thorac Oncol 2008; 3: 1191-3.

31. Lapuerta P, Martin SE, Ellison E. Fine-needle aspiration of peripheral lymph nodes in patients with tuberculosis and HIV. Am J Clin Pathol 1997; 107: 317-20.

32. Ulu-Kilic A, Gulen G, Sezen F, Kilic S, Sencan I. Tularemia in central Anatolia. Infection 2013; 41: 391-9.

33. Tuncer E, Onal B, Simsek G, et al. Tularemia: potential role of cytopathology in differential diagnosis of cervical lymphadenitis: multicenter experience in 53 cases and literature review. APMIS 2014; 122: 236-42.

34. Markoc F, Koseoglu RD, Koc S, Gurbuzler L. Tularemia in differential diagnosis of cervical lymphadenopathy: cytologic features of tularemia lymphadenitis. Acta Cytol 2014; 58: 23-8.

35. Hsueh EJ, Ko WS, Hwang WS, Yam LT. Fine-needle aspiration of histiocytic necrotizing lymphadenitis (Kikuchi's disease). Diagn Cytopathol 1993; 9: 448-52.

36. Viguer JM, Jimenez-Heffernan JA, Perez P, Lopez-Ferrer P, Gonzalez-Peramato P, Vicandi B. Fine-needle aspiration cytology of Kikuchis lymphadenitis: a report of ten cases. Diagn Cytopathol 2001; 25: 220-4.

37. Fite JJ, Maleki Z. Paraganglioma: cytomorphologic features, radiologic and clinical findings in 12 cases. Diagn Cytopathol 2018; 46: 473-81.

38. Annema JT, Veselic M, Rabe KF. Endoscopic ultrasound-guided fine-needle aspiration for the diagnosis of sarcoidosis. Eur Respir J 2005; 25: 405-9.

39. Vrbica Z, Boras Z, Rakusic N, et al. Necrotising sarcoid granulomatosis of the spinal cord: case report. Coll Antropol 2010; 34: 713-7. 